\title{
Editorial
}

\section{Rankings e outras medidas}

\author{
Manoel Tosta Berlinck*
}

A Revista Latinoamericana de Psicopatologia Fundamental (RLPF) consta das listas fornecidas pelo Scientific Journal Ranking (SJR), um serviço do Scimago Institutions Rankings (SCImago).

Esse portal utiliza informações da base de dados Scopus (www. scopus.com) para construir suas escalas.

Classificada como periódico de Psicologia Clínica, a RLPF ocupa, em 2015 , a $169^{\circ}$ posição numa lista mundial de 247 revistas. Em 2012, ela ocupava o $194^{\circ}$.

Segundo o SJR, a América Latina possui 8 revistas de Psicologia Clínica e a RLPF ocupa o $2^{\circ}$ lugar. Ela possui, ainda em 2015, um índice de impacto de 0,21 .

Nessa lista de 247 revistas, observa-se uma grande variedade de missões. Entretanto, elas possuem um substrato comum: valorizam o caso clínico como fundamento de suas pesquisas.

Tradicionalmente, é o caso e não a especulação teórica que caracteriza o conhecimento científico. Desde o início dessa tradição, o caso sempre foi o fundamento do conhecimento. É verdade que a ele se adiciona uma certa origem mitológica. Isso fica claro, por exemplo,

\footnotetext{
* Pontifícia Universidade Católica de São Paulo - PUC-SP (São Paulo, SP, Br).
} 
com a física moderna. Conta a lenda que as investigações de Isaac Newton nasceram de um episódio sui generis: a queda de uma maçã em sua cabeça, enquanto cochilava sob uma macieira.

Esse mito é elegante porque remete à natureza da observação científica. O fenômeno observado é sempre, inicialmente, uma ocorrência surpreendente que retira o cientista de um estado relaxado e desatento para outro e o lança para uma atenção reflexiva, com certa dose de angústia.

Assim, por exemplo, episódio semelhante ocorre na narração do caso "Katharina" relatado por Sigmund Freud no livro escrito em coautoria com Joseph Breuer, Estudos sobre a histeria (1893-1895/2016).

A observação científica ocorre, tudo indica, a partir de uma perturbação onde algo inesperado, mas familiar (Heimlich), perturba a serena tranquilidade em que se encontra o pesquisador. Tal episódio contém um componente enigmático e obscuro a solicitar um trabalho de significação que pode ser chamado de compreensão e, depois de esclarecido, pode ser chamado de explicação.

Esse perturbador componente enigmático e obscuro nada mais é do que uma discrepância entre aquilo que é e aquilo que deveria ser. Por exemplo, quando (prosseguindo no mito) Newton se põe a dormir sob uma carregada macieira, ele supõe que terá um momento de sossego. Entretanto, esse momento é interrompido por um fato (aquilo que é).

O conhecimento científico é, portanto, atividade antipreconceituosa que tem início com a aproximação da realidade pelo ser humano, pois o que "deveria ser" é construção imaginária influenciada por concepções ideais. Porém, não podemos nos esquecer que, sem "o que deveria ser" não há "o que é". Como a ciência valoriza "o que é", muitas vezes se esquece do "deveria ser". Entretanto, cada problema de investigação é a formulação precisa dessa discrepância.

A psicologia clínica precisa, pois, fazer jus a essa reclamação. Para isso, precisa estar constantemente referida à realidade, ou seja, ao caso, sem se esquecer do ideal (Magtaz \& Berlinck, 2012). Porém, é necessário repetir, quando se esquece do "que é", o discurso (logos) se afasta da ciência e se aproxima da ideologia.

Os rankings e outras medidas que colocam revistas científicas em escalas são indicadores de uma realidade: eles procuram medir (comparativamente) a significância, ou seja, o valor e a importância de um dado periódico em relação ao conjunto de revistas semelhantes. Talvez por isso sejam sempre insatisfatórios. 


\section{EDITORIAL}

\section{Referências}

Magtaz, A.C.; Berlinck, M.T. (2012, março). O caso clínico como fundamento da pesquisa em Psicopatologia Fundamental. Revista Latinoamericana de Psicopatologia Fundamental, São Paulo, 15(1), p. 72-82.

Freud, S.; Breuer, J. (2016). "Katharina...". In Estudos sobre a histeria (Laura Barreto, trad.). São Paulo: Companhia das Letras. (Trabalho original publicado em 1893-1895).

Citação/Citation: Berlinck, M.T. (2016, junho). Editorial. Rankings e outras medidas. Revista Latinoamericana de Psicopatologia Fundamental, 19(2), 211-213.

Editores do artigo/Editors: Prof. Dr. Manoel Tosta Berlinck e Profa. Dra. Sonia Leite

Recebido/Received: 5.4.2016/ 4.5.2016 Aceito/Accepted: 16.4.2016 / 4.16.2016

Copyright: (C) 2009 Associação Universitária de Pesquisa em Psicopatologia Fundamental/ University Association for Research in Fundamental Psychopathology. Este é um artigo de livre acesso, que permite uso irrestrito, distribuição e reprodução em qualquer meio, desde que o autor e a fonte sejam citados / This is an open-access article, which permits unrestricted use, distribution, and reproduction in any medium, provided the original authors and sources are credited.

\section{Manoel Tosta Berlinck}

Sociólogo; Psicanalista; Ph.D. pela Universidade de Cornell, Ithaca, N.Y., USA; Professor aposentado da Universidade Estadual de Campinas - Unicamp (Campinas, SP, Br); Professor do Programa de Estudos Pós-Graduados em Psicologia Clínica da Pontifícia Universidade Católica de São Paulo - PUC-SP (São Paulo, SP, Br), onde dirige o Laboratório de Psicopatologia Fundamental; presidente (2002-2014) da Associação Universitária de Pesquisa em Psicopatologia Fundamental, editor de Pulsional Revista de Psicanálise e da Revista Latinoamericana de Psicopatologia Fundamental; Membro da World Association of Medical Editors - WAME (Associação Mundial de Editores de Medicina); Ex-diretor da Livraria Pulsional e da Editora Escuta, autor de diversos livros e numerosos artigos.

Rua Tupi, 397/103

01233-001 São Paulo, SP

e-mail: mtberlin@uol.com.br

This is an open-access article, which permits unrestricted use, distribution,

\section{(cc) BY-NC} and reproduction in any medium for non-commercial purposes provided the original authors and sources are credited.

Rev. Latinoam. Psicopat. Fund., São Paulo, 19 (2), 211-213, jun.2016 